OPEN ACCESS

Edited by:

Lawrence Toll,

Florida Atlantic University,

United States

Reviewed by:

Diana Martinez,

Columbia University, United States

Taline Khroyan,

Cytogen Research and Development

Inc., United States

*Correspondence:

Vadim Yuferov

yuferov@rockefeller.edu

Specialty section: This article was submitted to

Addictive Disorders,

a section of the journal

Frontiers in Psychiatry

Received: 27 January 2018 Accepted: 24 May 2018

Published: 12 June 2018

Citation:

Yuferov V, Zhang Y, Liang Y, Zhao C, Randesi M and Kreek MJ (2018)

Oxycodone Self-Administration

Induces Alterations in Expression of Integrin, Semaphorin and Ephrin

Genes in the Mouse Striatum.

Front. Psychiatry 9:257.

doi: 10.3389/fpsyt.2018.00257

\section{Oxycodone Self-Administration Induces Alterations in Expression of Integrin, Semaphorin and Ephrin Genes in the Mouse Striatum}

\author{
Vadim Yuferov ${ }^{1 *}$, Yong Zhang ${ }^{1}$, Yupu Liang ${ }^{2}$, Connie Zhao ${ }^{3}$, Matthew Randesi ${ }^{1}$ and \\ Mary J. Kreek ${ }^{1}$ \\ ${ }^{1}$ Laboratory of the Biology of Addictive Diseases, The Rockefeller University, New York, NY, United States, ${ }^{2}$ Research \\ Bioinformatics, Clinical and Translational Science Award, The Rockefeller University, New York, NY, United States, ${ }^{3}$ Genomic \\ Resource Center, The Rockefeller University, New York, NY, United States
}

Oxycodone is one a commonly used medication for pain, and is also a widely abused prescription opioid, like other short-acting MOPr agonists. Neurochemical and structural adaptations in brain following chronic MOPr-agonist administration are thought to underlie pathogenesis and persistence of opiate addiction. Many axon guidance molecules, such as integrins, semaphorins, and ephrins may contribute to oxycodone-induced neuroadaptations through alterations in axon-target connections and synaptogenesis, that may be implicated in the behaviors associated with opiate addiction. However, little is known about this important area. The aim of this study is to investigate alterations in expression of selected integrin, semaphorin, ephrins, netrin, and slit genes in the nucleus accumbens (NAc) and caudate putamen (CPu) of mice following extended 14-day oxycodone self-administration (SA), using RNAseq.

Methods: Total RNA from the NAc and CPu were isolated from adult male C57BL/6J mice within $1 \mathrm{~h}$ after the last session of oxycodone in a 14-day self-administration paradigm (4h/day, $0.25 \mathrm{mg} / \mathrm{kg} /$ infusion, FR1) or from yoked saline controls. Gene expressions were examined using RNA sequencing (RNA-Seq) technology. RNA-Seq libraries were prepared using Illumina's TruSeq $®$ Stranded Total RNA LT kit. The reads were aligned to the mouse reference genome (version mm10) using STAR. DESeq2 was applied to the counts of protein coding genes to estimate the fold change between the treatment groups. False Discovery Rate (FDR) $q<0.1$ were used to select genes that have a significant expression change. For selection of a subset of genes related to axon guidance pathway, REACTOME was used.

Results: Among 38 known genes of the integrin, semaphorin, and ephrin gene families, RNA-seq data revealed up-regulation of six genes in the NAc: heterodimer receptor, integrins Itgal, Itgb2, and Itgam, and its ligand semaphorin Sema7a, two semaphorin receptors, plexins $P / x n d 1$ and $P / x d c 1$. There was down-regulation of eight genes in this region: two integrin genes Itga3 and Itgb8, semaphorins Sema3c, Sema4g, Sema6a, Sema6d, semaphorin receptor neuropilin Nrp2, and ephrin receptor Epha3. In the CPu, there were five differentially expressed axon guidance genes: up-regulation of three 
integrin genes, Itgal, Itgb2, Itga1, and down-regulation of Itga9 and ephrin Efna3 were thus observed. No significant alterations in expression of Netrin-1 or Slit were observed.

Conclusion: We provide evidence for alterations in the expression of selective axon guidance genes in adult mouse brain following chronic self-administration of oxycodone. Further examination of oxycodone-induced changes in the expression of these specific axon guidance molecules and integrin genes in relation to behavior may provide new insights into development of addiction to oxycodone.

Keywords: oxycodone, RNA seq, axon guidance genes, cell type enrichment, integrins

\section{INTRODUCTION}

Oxycodone is one of the most commonly use medications for pain, and like many short-acting MOPr agonists, it also has abuse potential. The neuroadaptations in specific brain regions following chronic opioid administration occur at the neurochemical and structural levels, and may underlie opioid use disorders. Like other drugs of abuse, opioids have the ability to cause neuroplasticity by altering morphology of dendrites and spines, which are the primary sites of excitatory synapses in brain regions involved in incentive motivation, reward, and learning (1). A decrease in the complexity of dendritic branching and number of dendritic spines on neurons specifically located in the nucleus accumbens (NAc) and cortex of rats was found following morphine self-administration $(2,3)$. Molecular mechanisms that underlie drug-induced structural alterations are still not fully understood. However, there are pharmacological and genetics evidence that the axon guidance genes may contribute to these morphological alterations $(4,5)$.

Researchers have identified five families of canonical guidance proteins: semaphorins, ephrins, slits, netrins, and integrins (4, 6). Proteins of the axon guidance gene family may contribute to oxycodone-induced neuroadaptations, through alterations in axon-target connections and synaptogenesis, and these may be implicated in the behaviors associated with opioid use disorders. Originally, integrins, semaphorins, ephrins, slits, and netrins with their cognate receptors were found to be implicated in establishing functional neural circuits, cell migration, and synapse formation during development (5). However, axon guidance molecules are also expressed in adult brain, and may contribute to alterations in neural circuit regulation, throughout axon pruning, synaptogenesis, dendrite, and spine morphogenesis. Several studies showed an implication of axon guidance proteins in neuroadaptation following drugs of abuse administration, and response to brain injury (7-12).

$\mathrm{EPH}$ receptor tyrosine kinases are divided into two classes, EPHA receptors (A1-A8, A10) and EPHB receptors (B1-B4, B6), based on their binding affinities for ligands ephrin-A (A1-A5) or ephrin-B (B1-B3) ligands (13). Eph receptors and ephrins mediate bidirectional signaling, being both membrane proteins. In general, cellular response to the Eph receptor activation is local actin fiber depolymerization, which results in rapid cytoskeletal collapse and loss of focal adhesions, leading to cell detachment. EphB1 receptor and ligand ephrin-B2 ligand are expressed in the midbrain dopaminergic neurons. Activation of the EphB1 inhibits the growth of neurites and induces the cell loss of substantia nigra, but not ventral tegmental, dopaminergic neurons (14). The same study showed that ephrin-B2 expression is upregulated by cocaine or amphetamine in the striatum of adult mice, suggesting that ephrin-B2/EphB1 interaction may play a role in drug-induced plasticity. Of interest, Liu et al showed that escalating morphine treatment up-regulates expression of EphB1 in the mouse spinal cord, and that EphB2 blocker (EphB2-Fc) attenuated most of naloxone-precipitated morphine withdrawal signs (15).

Twenty semaphorins fall into five classes, semaphorins 37 (16). Class 3 semaphorins are secreted proteins, classes 4-6 are transmembrane proteins, and semaphorin $7 \mathrm{~A}$ is linked to the plasma membrane via a glyco-phosphatidylinositol (GPI) anchor. Most of the effects of semaphorins are mediated by plexins, a group of nine transmembrane receptors that can be subdivided into four classes, plexins A-D, and two neuropilin receptors, Nrp1 and Nrp2. The semaphorin-plexin system is involved in multiple functions during development and in the adult organism, particularly in the nervous system, the immune system and during angiogenesis. Deregulation of semaphorin expression was documented in many pathological conditions such as ischemia, degenerative diseases, multiple sclerosis $(5,16)$. Semaphorins have also been shown to have immune regulatory functions in $\mathrm{B}$ and $\mathrm{T}$ cells. In vitro, Sema4d enhanced $\mathrm{B}$ cell survival, and play a role in monocytes and macrophages migration. Recently, Sema7A was identified as an effector molecule in T-cell-mediated inflammation through an integrinmediated mechanism (17).

Integrins are a large family of receptors for components of the extracellular matrix (ECM). Integrins are obligatory $\alpha \beta$-heterodimers that undergo large conformational changes in their extracellular domains in response to signaling events inside cells. In mammals, there are 18 different $\alpha$-subunits and 8 different $\beta$-subunits, which together generate 24 distinct integrin $\alpha \beta$-heterodimer receptor combinations (18). Intracellularly, integrins link to the actin cytoskeleton via adaptor proteins, such as talin and vinculin, and engage second messenger signaling cascades through several kinases such as Srk, ILK, FAK, and PI3K. Given the diversity of integrin effects, regional differences in receptor expression could be involved in activitydependent synaptic plasticity, including activity-dependent neural circuit adaptation, and in turn its dysfunctions might 
promote neurological disorders (19). In relation to drug addiction-like behavior, inhibition of integrin-linked kinase (ILK) in the rat NAc core blocked the induction of cocaine psychomotor sensitization, and prevented cocaine-induced increase in dendritic density and dendritic spine numbers (20). It has been shown that the basal levels of the integrin beta-1 (Itgb1) were elevated after chronic cocaine administration (11). Alpha and beta integrins are receptors for semaphorin 7A, and mediate its function (4). This supports potential involvement of integrins in the chronic cocaine-induced behaviors. However, there are no reports regarding an involvement of integrins in the opioid-induced pathology in humans or animal models.

Netrins play various important roles in the correct wiring of the nervous system during development (21). To date, several netrins have been described: netrin-1, netrin-3, netrin-4 and G-netrins. The most studied netrin-1 induces axon outgrowth via one of its receptors DCC (Deleted in Colorectal Cancer) in several types of neurons. Recent morphological analyses suggested a possibility of a shift in the function of netrin1 in cortical axons during development, from promotion of outgrowth to promotion of branch formation (22). Functionblocking experiments suggested that DCC may contribute not only to axon outgrowth but branching. There is no information on modulation of opioid-induced behaviors by netrin-1 or its receptor DCC expression. Of interest, in vitro treatment of neurons of dorsal root ganglion (DRG) with netrin-1 stimulates translation of the kappa opioid receptor (KOR), which activates its downstream target the focal adhesion kinase (FAK) (23).

Another class of axon guidance proteins is Robo receptor and its ligand Slit. The Slit/Robo pair not only functions in axon guidance in development but also in diverse processes in the CNS, like cell migration, axonal branching, axonal targeting or cell differentiation (24). In most vertebrates there are 3 Robo receptors expressed in CNS cells, Robo-1, Robo-2, and Robo3. Three Slit genes have been identified in mammals, Slit 1Slit-3. Full-length Slits can be cleaved by proteases generating shorter functional N-terminal isoforms (Slit1-N, Slit2-N, and Slit3-N). In relation to drug of abuse area, several studies showed their involvement in regulation of dopaminergic neurons (25, 26). For example, Slit-2 inhibits growth of tyrosine-ir positive $(\mathrm{TH}+)$ axons in primary cultures of the rat ventral midbrain. Similarly, Slit-2 reduced the number and length of $\mathrm{TH}+$ axons in explants from the ventral midbrain tissue of mouse brain (26). However, little is known about the effect of MOPr agonist self-administration on these important guidance molecules (10).

Nonmedical use and misuse of prescription opioids, including oxycodone is an increasing public health problem $(27,28)$. We hypothesize that specific representatives of the axon guidance gene family are implicated in development of neurobiological adaptation that occurs during chronic oxycodone self-administration. The aim of this study is to identify alterations in expression of specific axon guidance genes in the nucleus accumbens and caudate putamen of mice, following chronic oxycodone self-administration using RNA-seq technology.

\section{METHODS}

\section{Animals and Oxycodone Self-Administration Procedure}

Male adult (11 weeks old) C57BL/6J mice were obtained from Jackson Laboratory, Bar Harbor, ME. Animal care and experimental procedures were conducted according to the Guide for the Care and Use of laboratory Animals (Institute of Laboratory Animal Resources Commission on Life Sciences 2016). Animals had free access to food and water in a light $(12: 12 \mathrm{~h})$ reverse cycle, lights on at 7:00 p.m. and off at 7:00 a.m. Mice were handled prior to surgery. Catheter implantation for drug self-administration was carried out after acclimation of animals for 7 days. The experimental protocol used was approved by the Institutional Animal Care and Use Committee of the Rockefeller University.

\section{Oxycodone Self-Administration}

Details of surgery and catheter implantation, and subsequent the procedure of oxycodone self-administration (SA) in mice has been described previously (29). Briefly, the self-administration experiments were carried out in chamber ENV-307W (21.6, 17.8, and $12.7 \mathrm{~cm}$; Med Associates, St Albans, VT). A 4-h self-administration session was conducted once a day for 14 consecutive days with oxycodone, $n=6(0.25 \mathrm{mg} / \mathrm{kg} /$ infusion $)$ or yoked saline controls $(n=6)$.

\section{RNA Extraction}

Mice were sacrificed within $1 \mathrm{~h}$ after the last session of oxycodone self-administration, by exposure to $\mathrm{CO}_{2}$. The brain tissues of 12 mice (6 oxycodone and 6 yoked saline controls) were used for the RNA-seq study. Total RNA was isolated from the nucleus accumbens (NAc) and caudate putamen $(\mathrm{CPu})$ using the miRNeasy Kit (Qiagen, Valencia, CA). Agilent 6000 RNA Nano Chips were used to examine the integrity of RNA in samples.

\section{RNA-seq Library Preparation and Sequencing}

RNA-seq library preparation and sequencing of samples isolated from the CPu was performed by LC Sciences (Houston, TX), whereas RNA-seq library preparation and sequencing of RNA isolated from NAc was performed by the Genomic Resource Center at the Rockefeller University. Both RNA-seq libraries were prepared using Illumina's TruSeq ${ }^{\circledR}$ Stranded Total RNA LT kit following the manufacturer's protocol. Libraries were validated using Agilent Tape Station High-Sensitivity RNA kits and normalized. Libraries were multiplexed, four samples per lane, and sequenced. An Illumina HiSeq 2500 apparatus was used to obtain $100 \mathrm{bp}$ single end reads for samples from the nucleus accumbens, whereas Illumina HiSeq 2000 was used to obtain 100 bp paired-end reads for samples from the $\mathrm{CPu}$. All samples were analyzed exactly as described previously (30). Briefly, the reads were aligned to the mouse reference genome (version mm10) using STAR (31) aligner with default parameters. The alignment results were evaluated through RNA-SeQC (32). Aligned reads were then summarized through featureCounts (33) with the gene 
model from Ensemble (Mus_musculus GRCm38.75.gtf) at gene level.

Samples were normalized through a set of housekeeping genes Ppia, Gusb, and Gapdh as described previously (30). Principal Component Analysis (PCA) was then applied to normalized counts of all the samples by brain region, to detect outlier samples. In the $\mathrm{CPu}$, data from one saline control, and from one oxycodone-treated animals were thus excluded from downstream analysis. In the NAc, data from one oxycodonetreated animal was excluded from the downstream analysis.

\section{Axon Guidance Gene Selection}

REACTOME (linked to KEGG) was used to identify 416 genes in the NAc and 445 genes in $\mathrm{CPu}$ in the axon guidance canonical pathway (stable Identifier R-MMU-422475.1). Statistical significance and fold change of oxycodone-induced alterations in expression of 32 axon guidance-related genes (integrins, semaphorins and ephrins, and their receptors) were extracted from the total list of differentially expressed genes in the RNA-seq data for the NAc and $\mathrm{CPu}$ in this study (Supplement Tables 1s, $2 s$, respectively).

\section{Analyses of Cell-Type Specific Enrichment of Integrin, Semaphorin and Ephrin Gene Transcripts}

To examine whether DE axon guidance genes may produce their effect in cell type specific manner, we have studied potential enrichment in transcripts of the axon guidance genes in specific cell types such as astrocytes, neurons, microglial and endothelial cells. Publicly available RNA-Seq transcriptome data (34) were downloaded from GEO (GSE52564). For each gene of integrin, semaphorin and ephrin gene families, that had a significant change (FDR $<0.1$ ) in either $\mathrm{NAc}$ or $\mathrm{CPu}$, expression fold change of each cell type was calculated as described recently (34) (Table 2). For example, in astrocytes: FC = gene X's expression in astrocytes/average gene X's expression in all non-astrocyte cell types.

\section{STATISTICS}

\section{RNA-seq Differential Gene Expression Analysis}

We used DESeq2 (https://doi.org/10.1186/s13059-014-05508) (35), a method for differential analysis of RNA-seq data to estimate fold-change and significance testing. Specifically, DESeq2 estimate gene-wise log fold of changes (LFCs) between conditions from the standard Generalized Linear Model (GLM) fits to obtain maximum-likelihood estimates, and then fit a zero-centered normal distribution to the observed distribution of Maximum-likehood Estimate (MLE) over all genes. This distribution is used as a prior on LFC in a second round of GLM fits, and the maximum a posteriory (MAP) estimates are kept as final estimates of LFC. For significance testing, DESeq2 uses a Wald test: the shrunken estimate of LFC is divided by its standard error, resulting in a z-statistic, which is compared to a standard normal distribution. The Wald test $\mathrm{P}$ values from the subset of genes that pass an independent filtering step, are adjusted for multiple testing using the procedure of Benjamini and Hochberg (36).

DESeq2 was applied to the normalized counts to estimate the fold-change between the samples from mice that had selfadministered oxycodone versus those from yoked saline controls, using negative binomial distribution. An adjusted $p$-value of less than 0.1 (FDR $<0.1$ ) and fold change $\geq 15 \%$ were used to select genes that have a significant expression change.

\section{RESULTS}

\section{Extended Access Oxycodone Self-Administration}

Oxycodone self-administration behavior in the animals in this sample was reported in our previous publication (30). Our previous studies of oxycodone dose-response effects showed that a dose of $0.25 \mathrm{mg} / / \mathrm{kg}$ per infusion lead to escalation of oxycodone over the sessions (29). Animals showed a robust escalation of daily oxycodone intake across 14 consecutive daily sessions. A two-way ANOVA for drug condition (oxycodone or saline) $\times$ session (days 1-14), showed a significant main effect of drug condition $\left[F_{(1,252)}=672.6, p<0.0001\right]$ and a significant main effect of session $\left[F_{(13,252)}=2.359, p<0.01\right]$. The average amount of oxycodone self-administered for each mouse increased from $3 \mathrm{mg} / \mathrm{kg}$ on the 1 st session to $7.5 \mathrm{mg} / \mathrm{kg}$ on the last sessions. Oxycodone self-administering mice showed a much greater frequency of response on the active versus inactive holes. In contrast, yoked-saline control mice showed lower responding, and stayed stable across 14 daily sessions.

\section{Oxycodone-Induced Alterations in Expression of Integrin, Semaphorin and Ephrin Genes}

\section{Nucleus Accumbens (NAc)}

Among 38 integrin, semaphorin and ephrin genes selected for further analyses, we found significant alterations in 14 genes in the NAc at fold change $\geq 15 \%$, with a false discovery rate (FDR) of $<0.1$, of which six were up-regulated and 8 were downregulated (Table 1A). Among up-regulated genes, there were integrin receptors Itgal and Itgb2, and their ligand semaphorin Sema7a. There was also up-regulation of semaphorin receptors $P l x d c 1$ and Plxnd1, with concomitant lower levels in expression of their cognate ligands Sema3c, Sema4g, Sem6a, and Sema6d. In contrast to elevated expression of the receptor Plxd1, the receptor neuropilin Nrp2 was down-regulated. Two integrin genes, Itga3 and Itgb8 had lower level expression in the oxycodone treatment group, compared to the saline group, and only one gene from the ephrin receptor family, Epha3 was down-regulated in this group.

\section{Caudate-Putamen ( $\mathrm{CPu})$}

As observed above in the NAc, in this region there was strong up-regulation of three integrin genes, Itgal, Itgb2, and Itga1 (Table 1B). Among down-regulated genes, there were integrin Itga 9 and the ephrin receptor ligand, Efna3. 
TABLE 1 | Axon gudance and integrin genes with differential expression in the mouse nucleus accumbens and caudate putamen following 14 days of oxycodone self-administration (FDR $<0.1, \mathrm{FC}>15 \%)$.

\begin{tabular}{|c|c|c|c|c|c|}
\hline Gene symbol & Fold change & Direction & $p$-value & FDR & Gene name \\
\hline \multicolumn{6}{|c|}{ A. NUCLEUS ACCUBBENS } \\
\hline Itgal & 2.54 & $\uparrow$ & 0.00000 & 0.0000 & Integrin alpha $\mathrm{L}$ \\
\hline Itgb2 & 1.69 & $\uparrow$ & 0.00006 & 0.0068 & Integrin beta 2 \\
\hline Sema7a & 1.40 & $\uparrow$ & 0.00637 & 0.0910 & Semaphorin $7 a$ \\
\hline Plxdc1 & 1.32 & $\uparrow$ & 0.00102 & 0.0464 & Plexin dc1 \\
\hline Plxnd1 & 1.48 & $\uparrow$ & 0.00376 & 0.0693 & Plexin d1 \\
\hline Itgam & 1.29 & $\uparrow$ & 0.00519 & 0.0852 & Integrin alpha M \\
\hline Epha3 & 0.77 & $\downarrow$ & 0.00298 & 0.0620 & Ephrin receptor a3 \\
\hline Sema3c & 0.77 & $\downarrow$ & 0.00223 & 0.0618 & Semaphorin 3c \\
\hline Sema4g & 0.75 & $\downarrow$ & 0.00482 & 0.0821 & Semaphorin 4g \\
\hline Sema6a & 0.82 & $\downarrow$ & 0.00782 & 0.1050 & Semaphorin 6a \\
\hline Sema6d & 0.84 & $\downarrow$ & 0.06142 & 0.0583 & Semaphorin 6d \\
\hline Nrp2 & 0.61 & $\downarrow$ & 0.00165 & 0.0583 & Neuropilin 2 \\
\hline Itga3 & 0.77 & $\downarrow$ & 0.00244 & 0.0620 & Integrin a3 \\
\hline $\operatorname{ltg} b 8$ & 0.86 & $\downarrow$ & 0.00583 & 0.0861 & Integrin b8 \\
\hline Gene symbol & Fold change & Direction & $p$-value & FDR & Entrez gene name \\
\hline \multicolumn{6}{|c|}{ B. CAUDATE PUTAMEN } \\
\hline Itgal & 2.53 & $\uparrow$ & 0.00000 & 0.0002 & Integrin alpha L \\
\hline ltgb2 & 2.14 & $\uparrow$ & 0.00003 & 0.0041 & Integrin beta 2 \\
\hline $\operatorname{ltga1}$ & 1.48 & $\uparrow$ & 0.00060 & 0.0323 & Integrin alpha 1 \\
\hline Itga9 & 0.72 & $\downarrow$ & 0.00004 & 0.0042 & Integrin alpha 9 \\
\hline Efna3 & 0.71 & $\downarrow$ & 0.00185 & 0.0747 & Ephrin A3 \\
\hline
\end{tabular}

\section{Cell Type Specific Enrichment Analysis of Integrin, Semaphorin, and Ephrin Gene Transcripts}

Recently, an RNA-sequencing transcriptome and splicing database has been reported for purified representative populations of neurons, astrocytes, oligodendrocyte precursor cells, newly formed oligodendrocytes, myelinating oligodendrocytes, microglia, and endothelial cells from mouse cerebral cortex (34). This database provided a platform for analyzing and comparing transcription profiles for various cell classes in the brain herein. We have used this publicly available database to perform analyses of enrichment in expression levels of axon guidance genes that would be expected in astrocytes, neurons, microglial and endothelial cells. The analyses have revealed an enrichment of integrins Itgal, Itgb2, Itgam, and receptors $P l x d c 1$ and $P l x d c 2$ expression in microglia cells (Table 2). Similar analysis showed that ephrin Efna3, and its receptor Epha3, and semaphorins Sema3c and Sema4g are abundoned in neurons. Expression levels of semaphorins Sema7a and Sema3c, semaphorin receptor $\mathrm{Nrp} 2$, and integrin Itga 1 were enriched in endothelial cells. Astrocytes were enriched with semaphorin Sema6d.

\section{DISCUSSION}

In this study, we have for the first time RNA-seq technology applied to examine differential gene expression of the axon guidance gene family and integrins, in the NAc and $\mathrm{CPu}$ of adult male mice, following 14-day extended-access self-administration of oxycodone, compared with the yoked saline controls. This selfadministration regimen resulted in substantial daily intake and escalation of oxycodone across sessions (37).

We have found substantial difference in number of the differentially expressed axon guidance genes in response to the chronic oxycodone self-administration, 14 genes in the NAc, and five genes in the $\mathrm{CPu}$. This difference between these two regions could be due to, in part, difference in neuroanatomical structure and functions of ventral and dorsal striatum in the development of dependence to drugs of abuse, with the NAc implemented in drug rewards, and $\mathrm{CPu}$ in drug-induced habituation behavior (38). Earlier studies showed that in contrast to NAc, injections of morphine to $\mathrm{CPu}$ did not produce a condition place preference (39). This could be also a result of intrinsic differences in the dopamine fiber responsiveness that innervate these specific regions of the striatum as well as in dopamine transporters in regulation of drug-induced dopamine release. For example, repeated morphine administration at a dose of $1.0 \mathrm{mg} / \mathrm{kg}$ (s.c.) increased synaptic dopamine concentrations preferentially in the rat $\mathrm{NAc}$, not in $\mathrm{CPu}(40,41)$. After 15 days of withdrawal after 3 days of morphine treatment, challenge with $1 \mathrm{mg} / \mathrm{kg}$ (s.c.) morphine failed to significantly modify extracellular DA in the $\mathrm{CPu}$ of sensitized as well as in control rats (41).

We have found oxycodone-induced alterations in expression mainly in three axon guidance gene families such as integrins, semaphorins, and ephrins. These systems may contribute 
TABLE 2 | Cell type enrichment of integrin, semaphorin, and ephrin.

\begin{tabular}{|c|c|c|c|c|}
\hline \multicolumn{5}{|c|}{ Transcripts (log2 of Fold Enrichment) } \\
\hline Gene & Astrocytes (A) & Neurons (N) & $\begin{array}{l}\text { Microglia } \\
\text { (MGL) }\end{array}$ & $\begin{array}{l}\text { Endothelia } \\
\text { (Endo) }\end{array}$ \\
\hline Itgal & -2.235 & -2.235 & $2.956^{\mathrm{a}}$ & -1.419 \\
\hline Itga1 & -2.179 & -4.461 & -5.737 & 6.439 \\
\hline $\operatorname{ltga3}$ & -2.095 & 2.048 & -4.006 & 1.321 \\
\hline Itga9 & -5.707 & -3.4 & 2.081 & -2.568 \\
\hline Itgal.1 & -2.235 & -2.235 & 2.956 & -1.419 \\
\hline Itgam & -8.218 & -7.842 & 5.905 & -8.752 \\
\hline Itgb2 & -7.874 & -6.023 & 6.834 & -5.103 \\
\hline $\operatorname{ltgb2.1}$ & -7.874 & -6.023 & 6.834 & -5.103 \\
\hline Itgb8 & 0.978 & -1.988 & -6.774 & -6.7 \\
\hline Nrp2 & -2.55 & 0.197 & 0.802 & 1.935 \\
\hline Plxdc1 & -4.265 & 0.264 & 2.822 & 0.494 \\
\hline Plxdc2 & -1.234 & -1.446 & 3.347 & -2.651 \\
\hline Plxnd1 & -3.509 & 1.016 & -0.667 & 3.113 \\
\hline Sema3c & -3.559 & 1.725 & -5.425 & 3.192 \\
\hline Sema4g & -0.77 & 2.445 & -0.153 & -4.345 \\
\hline Sema6a & 0.642 & -0.977 & -7.241 & -0.245 \\
\hline Sema6d & 2.287 & -1.622 & -3.912 & 0.376 \\
\hline Sema7a & -3.782 & -2.209 & -3.772 & 4.542 \\
\hline Efna3 & -2.091 & 4.598 & -2.668 & -2.987 \\
\hline Epha3 & -2.207 & 4.406 & -3.799 & -3.525 \\
\hline
\end{tabular}

a Example of calculation of a fold enrichment of a gene in a specific cell type:

Log2 [expression of $X$ gene in astroglia divided by average expression of $X$ gene in nonastrocyte cell types $(N+M G L+E n d o)]$. Bolded numbers show the highest enrichment of $X$ gene transcripts in a specific cell type. Positive numbers indicate a higher abundance of gene $X$ expression in a particularly cell type, compared with its expression in other cells.

to oxycodone-induced neuroadaptations through alterations in axon-target connections and synaptogenesis and may be implicated in the behavioral and neurobiological adaptations occurring in opioid use disorders. No significant oxycodoneinduced alterations in expression of Netrin-1 or Slit were observed. We found here that integrins Itgal and Itgb2 have the greatest increase in expression in both the NAc and $\mathrm{CPu}$ immediately after chronic oxycodone SA. However, oxycodoneinduced increase of their potential ligand semaphorin Sema7a was observed only in the NAc, but not in the $\mathrm{CPu}$. In the adult brain, many integrins are present at high levels at synapses. The sequence arginine-glycine-aspartic acid RGD (42) was identified as a general integrin-binding motif. Application of soluble GRGDS (Gly-Arg-Gly-Asp-Ser) peptides completely abolished the mu opioid receptor agonist DAMGO inhibitory effect on cyclic AMP (cAMP) accumulation in bradykininprimed trigeminal ganglia neurons $(43,44)$. This suggests that activation of specific integrins at focal adhesions may modulate the mu opioid receptor signaling by altering interactions with $G$ proteins. Also, RGD peptides, or anti-integrin antibodies block N-methyl-D-aspartate (NMDA)-mediated excitatory postsynaptic currents in hippocampal neurons (45), suggesting that RGD-binding integrins are important in neurotransmission.
We have found only one gene from the ephrin receptor family, Epha3, which was down-regulated in the NAc of oxycodone-treated mice. In other studies, similar down regulation in the expression of ephrin genes in the rat NAc was observed at $24 \mathrm{~h}$ after secession of heroin self-administration (6 h/day for 5 days) (12). In contrast, cocaine treatment increased expression of many ephrin and ephrin receptor in the rat and mouse striatum and hippocampus $(7,14)$ and in striatum of nonhuman primates (46). Alterations in expression of the Eph/ephrin genes have also been linked to neuropathology ranging from inhibition of neural repair after traumatic injury and stroke to neurodegenerative diseases $(47,48)$. Ephrin receptors and their ligands are implicated in dendritic spine morphology throughout an interaction with integrins. For instance, activation of the receptor EphA4 by ephrinA3 inhibits activity of integrin Itgb1 and downstream signaling, and leads to decreases spine length and density (49). Transgenic overexpression of ephrinA3 in astrocytes reduces glutamate transporter levels and elevates extracellular glutamate concentrations (50). In contrast, loss of ephrin-A3 raises glutamate transporter currents in astrocytes. Functionally, EphA4 and ephrinA3 modulate transporter glutamate currents in astrocytes.

Previously, microarray studies of morphine-treated mice showed alterations in expression of genes related to the semaphorin pathway in the NAc such as Sema3f, Sema4b, sema6c, Sema6d, Sema7a, and Plxna3 (10) and Sema6a (44). Heroin self-administration induced downregulation of Sema5a, Sema6c and receptor Plxnb1 in the rat NAc (12). Consistent with these earlier reports, in this study we have found oxycodoneinduced downregulation of Sema3c, Sema4g, Sema6a, Sema6d, and upregulation Sema7a in the mouse NAc. Our results are also consistent with alterations in the expression of semaphorins and their receptors in post-mortem brain of patients chronically exposed to alcohol or cocaine (51), particularly upregulation of SEMA7A and plexin PLXDC1, and down-regulation SEMA4B in hippocampus. Alterations in expression of semaphorins and their receptors were documented in many pathological conditions such as ischemia, degenerative diseases, multiple sclerosis (5).

Early studies showed that chronic morphine modulate both adaptive and innate immune systems, as well as activate neuroinflammation (52). Several studies showed that this effect of morphine on immune system is mediated by the central MOPr, and can be antagonized by naltrexone $(53,54)$. Several studies showed that microglia, astrocytes, oligodendrocytes, and endothelial cells actively respond to opioids by producing an inflammatory immune response $(55,56)$. Recently, we have reported mRNA levels of numerous genes related to the inflammation and immune functions changed as a result of oxycodone self-administration, in the $\mathrm{CPu}$ and NAc (30). We have found oxycodone-induced upregulation in the NAc of many glial- and immune cell-specific genes, such as the chemokine receptor Ccr5, chemokine Ccl 12, toll-like receptor Tlr7, interleukin Il1b, interleukin-17 receptor, antigen CD14, antigen CD163, complement component $1 \mathrm{Clqc}$, interferon regulatory factor Irf1, and others. Astrocytes and microglia 
release several neuroactive molecules, such as glutamate, Dserine, ATP, GABA, TNFa, that can actively regulate many aspects of neuronal function, including neurotransmitter release, gene regulation, dendritic morphology, and synaptic connectivity (57).

Semaphorins were shown to be involved in initiation of the immune response in brain (58), and alterations in their expression may be related to the oxycodone-induced changes in inflammation/immune gene expression found in this study. Sema7A has been identified as an effector molecule in T-cell-mediated inflammation through an integrin-mediated mechanism, reviewed in (17). Of interest, many immune proteins have been found in healthy, uninfected nervous system, and they may participate in regulation of neuronal functions, including neurotransmitter release, dendritic morphology, and synaptic transmission (59-61).

Several studies proposed axon guidance molecules for contact interaction of neuronal and glial cells (13). The oxycodoneinduced differential expression of integrins, semaphorins, and ephrins in ventral and dorsal regions of the mouse striatum implies that they likely participate in the altered communication occurring between neurons and glial cells. Therefore, an identification of cell type specificity of axon guidance gene expression would help in understanding of their specific roles in drug-induced alterations in neuronal activity. We did not perform a cell sorting procedure of brain tissues in our experiments. However, our bioinformatics analysis of oxycodone-induced differentially expressed axon guidance genes showed that their mRNA enrichment varied among neuronal, astrocyte, microglial and endothelial cells, supporting their pleiotropic functions in adaptation to chronic oxycodone treatment.

Since gene expression changes were examined immediately after 14 consecutive days of chronic oxycodone selfadministration, it is also not clear whether the changes in axon guidance gene expression are long-lasting, which may play an important role in drug-induced adaptation. The exact molecular mechanisms of regulation of neurotransmission (e.g., dopaminergic, GABAergic, serotoninergic) by different axon

\section{REFERENCES}

1. Russo SJ, Dietz DM, Dumitriu D, Morrison JH, Malenka RC, Nestler EJ. The addicted synapse: mechanisms of synaptic and structural plasticity in nucleus accumbens. Trends Neurosci. (2010) 33:267-76. doi: 10.1016/j.tins.2010.02.002

2. Robinson TE, Gorny G, Savage VR, Kolb B. Widespread but regionally specific effects of experimenter- versus self-administered morphine on dendritic spines in the nucleus accumbens, hippocampus, and neocortex of adult rats. Synapse (2002) 46:271-9. doi: 10.1002/syn.10146

3. Ballesteros-Yanez I, Ambrosio E, Benavides-Piccione R, Perez J, Torres I, Miguens $\mathrm{M}$, et al. The effects of morphine self-administration on cortical pyramidal cell structure in addiction-prone lewis rats. Cereb Cortex (2007) 17:238-49. doi: 10.1093/cercor/bhj142

4. Pasterkamp RJ. Getting neural circuits into shape with semaphorins. Nat Rev Neurosci. (2012) 13:605-18. doi: 10.1038/nrn3302

5. Van Battum EY, Brignani S, Pasterkamp RJ. Axon guidance proteins in neurological disorders. Lancet Neurol. (2015) 14:532-46. doi: 10.1016/S1474-4422(14)70257-1 guidance molecules remain unknown. However, it is known that axon guidance molecules are involved in glutamatergic transmission and long term potentiation (60). Therefore, oxycodone induced alterations in axon guidance gene expression may be relevant to neuronal plasticity which may occur in addictive-like state $(1,62)$. This is the first RNAseq study on the impact of a chronic period of oxycodone self-administration, a widely abused prescription drug on expression of axon guidance genes in the mouse brain.

In conclusion, we have found alterations in expression of specific axon guidance genes in the mouse striatum following chronic oxycodone self-administration. Although, their exact functions in drug taking or drug seeking behaviors are not known, these proteins are promising targets for further studies and development of treatment of oxycodone addiction.

\section{AUTHOR CONTRIBUTIONS}

$\mathrm{YZ}$ and MK designed the experiment. $\mathrm{YZ}$ and $\mathrm{CZ}$ performed experiments. YL, MR, and VY analyzed data, and drafted the manuscript.

\section{ACKNOWLEDGMENTS}

This work was supported by NIH 1R01DA029147 (YZ) and the Dr. Miriam and Sheldon G. Adelson Medical Research Foundation (MK). YL is supported in part by grant \# UL1 TR001866 from the National Center for Advancing Translational Sciences (NCATS, National Institutes of Health (NIH) Clinical and Translational Science Award (CTSA) program (PI-B. Coller, $\mathrm{MD})$. The authors thank Dr. Eduardo Butelman for reviewing the manuscript.

\section{SUPPLEMENTARY MATERIAL}

The Supplementary Material for this article can be found online at: https://www.frontiersin.org/articles/10.3389/fpsyt. 2018.00257/full\#supplementary-material
6. Pasterkamp RJ, Kolodkin AL. SnapShot: axon guidance. Cell (2013) 153:494e1-2. doi: 10.1016/j.cell.2013.03.031

7. Bahi A, Dreyer JL. Cocaine-induced expression changes of axon guidance molecules in the adult rat brain. Mol Cell Neurosci. (2005) 28:275-91. doi: 10.1016/j.men.2004.09.011

8. Xiao D, Miller GM, Jassen A, Westmoreland SV, Pauley D, Madras BK. Ephrin/Eph receptor expression in brain of adult nonhuman primates: implications for neuroadaptation. Brain Res. (2006) 1067:67-77. doi: 10.1016/j.brainres.2005.10.073

9. Jassen AK, Yang H, Miller GM, Calder E, Madras BK. Receptor regulation of gene expression of axon guidance molecules: implications for adaptation. $\mathrm{Mol}$ Pharmacol. (2006) 70:71-7. doi: 10.1124/mol.105.021998

10. Grice DE, Reenila I, Mannisto PT, Brooks AI, Smith GG, Golden GT, et al. Transcriptional profiling of C57 and DBA strains of mice in the absence and presence of morphine. BMC Genomics (2007) 8:76. doi: $10.1186 / 1471-2164-8-76$

11. Wiggins AT, Pacchioni AM, Kalivas PW. Integrin expression is altered after acute and chronic cocaine. Neurosci Lett. (2009) 450:321-3. doi: $10.1016 /$ j.neulet.2008.12.006 
12. Imperio CG, McFalls AJ, Colechio EM, Masser DR, Vrana KE, Grigson PS, et al. Assessment of individual differences in the rat nucleus accumbens transcriptome following taste-heroin extended access. Brain Res Bull. (2016) 123:71-80. doi: 10.1016/j.brainresbull.2015.12.005

13. Murai KK, Pasquale EB. Eph receptors and ephrins in neuron-astrocyte communication at synapses. Glia (2011) 59:1567-78. doi: 10.1002/glia.21226

14. Yue Y, Widmer DA, Halladay AK, Cerretti DP, Wagner GC, Dreyer JL, et al. Specification of distinct dopaminergic neural pathways: roles of the Eph family receptor EphB1 and ligand ephrin-B2. J Neurosci. (1999) 19:2090-101. doi: 10.1523/JNEUROSCI.19-06-02090.1999

15. Liu WT, Li HC, Song XS, Huang ZJ, Song XJ. EphB receptor signaling in mouse spinal cord contributes to physical dependence on morphine. FASEB J. (2009) 23:90-8. doi: 10.1096/fj.08-114462

16. Worzfeld T, Offermanns S. Semaphorins and plexins as therapeutic targets. Nat Rev Drug Discov. (2014) 13:603-21. doi: 10.1038/nrd4337

17. Roth L, Koncina E, Satkauskas S, Cremel G, Aunis D, Bagnard D. The many faces of semaphorins: from development to pathology. Cell Mol Life Sci. (2009) 66:649-66. doi: 10.1007/s00018-008-8518-z

18. Hynes RO. Integrins: bidirectional, allosteric signaling machines. Cell (2002) 110:673-87. doi: 10.1016/S0092-8674(02)00971-6

19. Park YK, Goda Y. Integrins in synapse regulation. Nat Rev Neurosci. (2016) 17:745-56. doi: 10.1038/nrn.2016.138

20. Chen Q, Xiong X, Lee TH, Liu Y, Wetsel WC, Zhang X. Neural plasticity and addiction: integrin-linked kinase and cocaine behavioral sensitization. $J$ Neurochem (2008) 107:679-89. doi: 10.1111/j.1471-4159.2008.05619.x

21. Barallobre MJ, Pascual M, Del Rio JA, Soriano E. The Netrin family of guidance factors: emphasis on Netrin-1 signalling. Brain Res Brain Res Rev. (2005) 49:22-47. doi: 10.1016/j.brainresrev.2004.11.003

22. Matsumoto $H$, Nagashima $M$. Shift in the function of netrin-1 from axon outgrowth to axon branching in developing cerebral cortical neurons. BMC Neurosci. (2017) 18:74. doi: 10.1186/s12868-017-0 392-x

23. Tsai NP, Bi J, Loh HH, Wei LN. Netrin-1 signaling regulates de novo protein synthesis of kappa opioid receptor by facilitating polysomal partition of its mRNA. J Neurosci. (2006) 26:9743-9. doi: 10.1523/JNEUROSCI.3014-06.2006

24. Chedotal A. Slits and their receptors. Adv Exp Med Biol. (2007) 621:65-80. doi: 10.1007/978-0-387-76715-4_5

25. Cornide-Petronio ME, Barreiro-Iglesias A. Role of slit and robo proteins in the development of dopaminergic neurons. Dev Neurosci. (2013) 35:285-92. doi: $10.1159 / 000351023$

26. Dugan JP, Stratton A, Riley HP, Farmer WT, Mastick GS. Midbrain dopaminergic axons are guided longitudinally through the diencephalon by Slit/Robo signals. Mol Cell Neurosci. (2011) 46:347-56. doi: 10.1016/j.mcn.2010.11.003

27. Comer SD, Sullivan MA, Whittington RA, Vosburg SK, Kowalczyk WJ. Abuse liability of prescription opioids compared to heroin in morphinemaintained heroin abusers. Neuropsychopharmacology (2008) 33:1179-91. doi: 10.1038/sj.npp.1301479

28. Paulozzi LJ, Strickler GK, Kreiner PW, Koris CM. Centers for disease c, and prevention, controlled substance prescribing patterns-prescription behavior surveillance system, eight states, 2013. MMWR Surveill Summ. (2015) 64:1-14. doi: 10.15585/mmwr.ss6409a1

29. Zhang Y, Picetti R, Butelman ER, Schlussman SD, Ho A, Kreek MJ. Behavioral and neurochemical changes induced by oxycodone differ between adolescent and adult mice. Neuropsychopharmacology (2009) 34:912-22. doi: 10.1038/npp.2008.134

30. Zhang Y, Liang Y, Levran O, Randesi M, Yuferov V, Zhao C, et al. Alterations of expression of inflammation/immune-related genes in the dorsal and ventral striatum of adult $\mathrm{C} 57 \mathrm{BL} / 6 \mathrm{~J}$ mice following chronic oxycodone self-administration: a RNA sequencing study. Psychopharmacology (2017) 234:2259-75. doi: 10.1007/s00213-017-4657-y

31. Dobin A, Davis CA, Schlesinger F, Drenkow J, Zaleski C, Jha S. STAR: ultrafast universal RNA-seq aligner. Bioinformatics (2013) 29:15-21. doi: 10.1093/bioinformatics/bts635

32. DeLuca DS, Levin JZ, Sivachenko A, Fennell T, Nazaire MD, Williams C, et al. RNA-SeQC: RNA-seq metrics for quality control and process optimization. Bioinformatics (2012) 28:1530-2. doi: 10.1093/bioinformatics/ bts 196
33. Liao Y, Smyth GK, Shi W. Featurecounts: an efficient general purpose program for assigning sequence reads to genomic features. Bioinformatics (2014) 30:923-30. doi: 10.1093/bioinformatics/btt656

34. Zhang Y, Chen K, Sloan SA, Bennett ML, Scholze AR, O'Keeffe S, et al. An RNA-sequencing transcriptome and splicing database of glia, neurons, and vascular cells of the cerebral cortex. J Neurosci. (2014) 34:11929-47. doi: 10.1523/JNEUROSCI.1860-14.2014

35. Love MI, Huber W, Anders S. Moderated estimation of fold change and dispersion for RNA-seq data with DESeq2. Genome Biol (2014) 15:550. doi: 10.1186/s13059-014-0550-8

36. Benjamini Y, Hochberg Y. Controlling the false discovery rate - a practical and powerful approach to multiple testing. J R Stat Soc Ser B Methodol. (1995) 57:289-300.

37. Zhang Y, Mayer-Blackwell B, Schlussman SD, Randesi M, Butelman ER, Ho A, et al. Extended access oxycodone self-administration and neurotransmitter receptor gene expression in the dorsal striatum of adult C57BL/6 J mice. Psychopharmacology (2014) 231:1277-87. doi: 10.1007/s00213-013-3306-3

38. Everitt BJ, Robbins TW. From the ventral to the dorsal striatum: devolving views of their roles in drug addiction. Neurosci Biobehav Rev. (2013) 37:1946-54. doi: 10.1016/j.neubiorev.2013.02.010

39. Olmstead MC, Franklin KB. The development of a conditioned place preference to morphine: effects of microinjections into various CNS sites. Behav Neurosci. (1997) 111:1324-34. doi: 10.1037/0735-7044.111.6.1324

40. Di Chiara G, Imperato A. Drugs abused by humans preferentially increase synaptic dopamine concentrations in the mesolimbic system of freely moving rats. Proc Natl Acad Sci USA. (1988) 85:5274-8. doi: 10.1073/pnas.85.14.5274

41. Cadoni C, Di Chiara G. Reciprocal changes in dopamine responsiveness in the nucleus accumbens shell and core and in the dorsal caudateputamen in rats sensitized to morphine. Neuroscience (1999) 90:447-55. doi: 10.1016/S0306-4522(98)00466-7

42. Brudzynski SM, Gibson B, Silkstone M, Burgdorf J, Kroes RA, Moskal JR, et al. Motor and locomotor responses to systemic amphetamine in three lines of selectively bred Long-Evans rats. Pharmacol Biochem Behav (2011) 100:119-24. doi: 10.1016/j.pbb.2011.08.006

43. Berg KA, Zardeneta G, Hargreaves KM, Clarke WP, Milam SB. Integrins regulate opioid receptor signaling in trigeminal ganglion neurons. Neuroscience (2007) 144:889-97. doi: 10.1016/j.neuroscience.2006.10.033

44. Tapocik JD, Luu TV, Mayo CL, Wang BD, Doyle E, Lee AD, et al. Neuroplasticity, axonal guidance and micro-RNA genes are associated with morphine self-administration behavior. Addict Biol (2013) 18:480-95. doi: $10.1111 /$ j.1369-1600.2012.00470.x

45. Chavis P, Westbrook G. Integrins mediate functional pre- and postsynaptic maturation at a hippocampal synapse. Nature (2001) 411:317-21. doi: $10.1038 / 35077101$

46. Saka E, Goodrich C, Harlan P, Madras BK, Graybiel AM. Repetitive behaviors in monkeys are linked to specific striatal activation patterns. J Neurosci (2004) 24:7557-65. doi: 10.1523/JNEUROSCI.1072-04.2004

47. Boyd AW, Bartlett PF, Lackmann M. Therapeutic targeting of EPH receptors and their ligands. Nat Rev Drug Discov (2014) 13:39-62. doi: 10.1038/nrd4175

48. Barquilla A, Pasquale EB. Eph receptors and ephrins: therapeutic opportunities. Annu Rev Pharmacol Toxicol (2015) 55:465-87. doi: 10.1146/annurev-pharmtox-011112-140226

49. Klein R. Bidirectional modulation of synaptic functions by Eph/ephrin signaling. Nat Neurosci (2009) 12:15-20. doi: 10.1038/nn.2231

50. Carmona MA, Murai KK, Wang L, Roberts AJ, Pasquale EB. Glial ephrin-A3 regulates hippocampal dendritic spine morphology and glutamate transport. Proc Natl Acad Sci USA. (2009) 106:12524-9. doi: 10.1073/pnas.0903328106

51. Zhou Z, Yuan Q, Mash DC, Goldman D. Substance-specific and shared transcription and epigenetic changes in the human hippocampus chronically exposed to cocaine and alcohol. Proc Natl Acad Sci USA. (2011) 108:6626-31. doi: $10.1073 /$ pnas. 1018514108

52. Wang X, Loram LC, Ramos K, de Jesus AJ, Thomas J, Cheng K, et al. Morphine activates neuroinflammation in a manner parallel to endotoxin. Proc Natl Acad Sci USA. (2012) 109:6325-30. doi: 10.1073/pnas.1200130109

53. Hernandez MC, Flores LR, Bayer BM. Immunosuppression by morphine is mediated by central pathways. J Pharmacol Exp Ther. (1993) 267:1336-41.

54. Lysle DT, Coussons ME, Watts VJ, Bennett EH, Dykstra LA. Morphineinduced alterations of immune status: dose dependency, compartment 
specificity and antagonism by naltrexone. J Pharmacol Exp Ther. (1993) 265:1071-8.

55. Jacobsen JH, Hutchinson MR, Mustafa S. Drug addiction: targeting dynamic neuroimmune receptor interactions as a potential therapeutic strategy. Curr Opin Pharmacol. (2016) 26:131-7. doi: 10.1016/j.coph.2015.10.010

56. Lacagnina MJ, Rivera PD, Bilbo SD. Glial and neuroimmune mechanisms as critical modulators of drug use and abuse. Neuropsychopharmacology (2017) 42:156-77. doi: 10.1038/npp.2016.121

57. Eroglu C, Barres BA. Regulation of synaptic connectivity by glia. Nature (2010) 468:223-31. doi: 10.1038/nature09612

58. Suzuki K, Kumanogoh A, Kikutani H. Semaphorins and their receptors in immune cell interactions. Nat Immunol. (2008) 9:17-23. doi: 10.1038/ni1553

59. Boulanger LM. Immune proteins in brain development and synaptic plasticity. Neuron (2009) 64:93-109. doi: 10.1016/j.neuron.2009. 09.001

60. Filosa A, Paixao S, Honsek SD, Carmona MA, Becker L, Feddersen B, et al. Neuron-glia communication via EphA4/ephrin-A3 modulates LTP through glial glutamate transport. Nat Neurosci. (2009) 12:1285-92. doi: $10.1038 / \mathrm{nn} .2394$
61. Paixao S, Klein R. Neuron-astrocyte communication and synaptic plasticity. Curr Opin Neurobiol. (2010) 20:466-73. doi: 10.1016/j.conb.2010. 04.008

62. Rich MT, Torregrossa MM. Molecular and synaptic mechanisms regulating drug-associated memories: Towards a bidirectional treatment strategy. Brain Res Bull. (2017). doi: 10.1016/j.brainresbull.2017.09.003. [Epub ahead of print].

Conflict of Interest Statement: The authors declare that the research was conducted in the absence of any commercial or financial relationships that could be construed as a potential conflict of interest.

Copyright (c) 2018 Yuferov, Zhang, Liang, Zhao, Randesi and Kreek. This is an open-access article distributed under the terms of the Creative Commons Attribution License (CC BY). The use, distribution or reproduction in other forums is permitted, provided the original author(s) and the copyright owner are credited and that the original publication in this journal is cited, in accordance with accepted academic practice. No use, distribution or reproduction is permitted which does not comply with these terms. 